\title{
Management of Potential Organ Donor: Indian Society of Critical Care Medicine: Position Statement
}

\begin{abstract}
Rahul Anil Pandit, Kapil G. Zirpe', Sushma Kirtikumar Gurav², Atul P. Kulkarni³, Sunil Karnath4, Deepak Govil ${ }^{5}$, Babu Abhram ${ }^{6}$, Yatin Mehta7 , Abinav Gupta ${ }^{8}$, Ashit Hegde ${ }^{9}$, Vijaya Pati ${ }^{10}$, Pradip Bhatacharya ${ }^{11}$, Subhal Dixit ${ }^{12}$, Srinivas Samavedan ${ }^{13}$, Subhash Todi ${ }^{14}$

Director, Intensive Care Unit, Fortis Hospital, ${ }^{9}$ Consultant, P. D. Hinduja Hospital, ${ }^{3}$ Department of Anaesthesiology, Critical Care and Pain, Division of Critical Care Medicine, Tata Memorial Hospital, ${ }^{10}$ Department of Anesthesia, Tata Memorial Hospital, Mumbai, ${ }^{1}$ Director, Neurotrauma Unit, Grant Medical Foundation, Ruby Hall Clinic, ${ }^{2}$ Consultant, Neurotrauma Unit, Ruby Hall Clinic, ${ }^{12}$ Director, Intensive Care Unit, Sanjeevan and MJM Hospital, Pune, Maharashtra, ${ }^{4}$ Department of Critical Care Medicine, Manipal Hospital, Bengaluru, Karnataka, ${ }^{7}$ Chairman, Institute of Anaesthesiology and Critical Care, Medanta - The Medicity, ${ }^{5}$ Director, Intensive Care Unit, Medanta Institute of Critical Care and Anaesthesiology, Medanta - The Medicity, Gurgaon, Haryana, ${ }^{6}$ Department of Critical Care, Apollo Hospital, Chennai, Tamil Nadu, ${ }^{8} \mathrm{Head}$, Critical Care and Emergency, Sharda Hospital, School of Medical Sciences and Research, Sharda University, Greater Noida, Uttar Pradesh, ${ }^{11}$ Director, Emergency Services and Critical Care, Chirayu Medical College and Hospital, Bhopal, Madhya Pradesh, ${ }^{13}$ Department of Critical Care, Virinchi Hospital, Hyderabad, Telangana, ${ }^{14}$ Department of Critical Care, A.M.R.I. Hospital, Kolkata, West Bengal, India
\end{abstract}

\section{Purpose and Scope of the Statement}

The position statement for management of organ donors is prepared by the Indian Society of Critical Care Medicine (ISCCM) with an objective of providing the standard perspective for the management of potential organ/tissue donors after brain death in adults only, regardless of the availability of technology. This document should be used as guidance only and does not a substitute for proper clinical decision-making in particular circumstances of any case. The endorsement of ISCCM does not imply that the statements given in the document are applicable in all or in a particular case; however, they may provide guidance for the users thus utilizing maximum organs from brain-dead patients. Thus, care of potential brain-dead organ donor is "caring for multiple recipients" [Table 1].

The grading of recommendations is as follows:

A. We recommend

B. We suggest.

Quality of evidence is:

1. High to moderate

2. Moderate to low.

\section{INTRODUCTION}

In India, the deceased donor organ donation rate is only 0.8 per million (while USA at 25.6 per million, UK at 18.3 per million, and Spain at 32 per million). ${ }^{[1]}$

\begin{tabular}{|l|l|}
\hline \multicolumn{2}{|c|}{ Access this article online } \\
\hline Quick Response Code: & Website: \\
\hline & www.ijccm.org \\
\hline & \\
\hline
\end{tabular}

On the background of increasing organ demand, ${ }^{[2]}$ compared to the number of organs available for transplantation, the responsibility to care for potential donor increases. A multidisciplinary team approach is necessary for successful organ donation. ${ }^{[3]}$ The physiology of all the available organs in the donor should be normalized and maintained till the time of organ retrieval. Often older people and marginal donors are also potential donor candidates, such cases need to be managed carefully, to improve the conversion rate and graft survival after donation. ${ }^{[2]}$ Intensivists play a vital role in identification, declaration of brain death, and providing medical care to potential organ donors, thereby improving rates of graft survival, i.e., quality of organ donation. ${ }^{[3-5]}$

The ISCCM has recently released guidelines for end-of-life and palliative care in Indian intensive care units. ${ }^{[6]}$ However, currently, there are no guidelines for the identification of potential donor and management of identified potential organ donor in India.

\section{Potential Organ Donor}

A potential organ donor is defined by the presence of either brain death or a catastrophic injury to the brain which could

Address for correspondence: Dr. Sushma K. Gurav Neurotrauma Unit, Ruby Hall Clinic, Pune, Maharashtra, India. E-mail: kirtisush_gurav@yahoo.co.in

This is an open access article distributed under the terms of the Creative Commons Attribution-NonCommercial-ShareAlike 3.0 License, which allows others to remix, tweak, and build upon the work non-commercially, as long as the author is credited and the new creations are licensed under the identical terms.

For reprints contact: reprints@medknow.com

How to cite this article: Pandit RA, Zirpe KG, Gurav SK, Kulkarni AP, Karnath S, Govil D, et al. Management of potential organ donor: Indian Society of Critical Care Medicine: Position statement. Indian J Crit Care Med 2017;21:303-16. 


\begin{tabular}{l}
\hline Table 1: Points covered \\
\hline Definition of potential organ donor \\
Definition of brain death and importance of brain stem death \\
Declaration of brain death and tests done for confirmation of brain death \\
Legal aspects of organ donation in India \\
Physiological changes in brain-dead patients and complications \\
Medical management of potential organ donor \\
List of drugs causing hepatic and renal injury/damage \\
\hline
\end{tabular}

progress beyond reversibility and may fulfill brain death criteria. ${ }^{[7]}$

\subsection{Milestones}

Historically, death was defined by the presence of putrefaction or decapitation, failure to respond to painful stimuli, or the apparent loss of observable cardiorespiratory action. However, with development in resuscitation measures and invention of mechanical ventilators, respiratory arrest was prevented. Vital functions can now be maintained artificially after the brain has ceased to function. Increasing incidence of medicolegal cases necessitated the definition of brain death. ${ }^{[8-10]}$

In 1959, Mollaret and Goulon coined the term on brain death "le coma dèèpasse."

In 1968, an ad hoc committee at Harvard Medical School reexamined the definition of brain death.

Uniform determination of death act gave statutory recognition to the concept of brain death and equated this concept with traditional cardiorespiratory death. The fundamental tenet of this criterion is based on a "cessation of the integrative functioning of the organism as whole." An individual who has sustained either (1) irreversible cessation of circulatory and respiratory functions or (2) irreversible cessation of all functions of the entire brain, including the brain stem is dead.

In 1976, the Conference of Medical Royal colleges published the statement on the diagnosis of brain death, and clinical diagnostic testing for brain death became more refined.

In 1981, the US President's Commission for the Study of Ethical Problems in Medicine and Biomedical and Behavioral Research published guidelines regarding brain death. The guidelines recommended the use of supplementary diagnostic tests to augment the clinical examination in brain death.

India follows the UK code. In India, the legal framework for organ donation is in place. According to the Transplantation of Human Organ Act (THOA-1994) legislation, deceased donation is a legal option (THOA 1994). ${ }^{[11,12]}$

The Central Government has established a National Human Organs and Tissues Removal and Storage Network named NOTTO, which stands for National Organ and Tissue Transplant Organization. NOTTO has five regional networks Regional Organ and Tissue Transplant Organization (ROTTO), and each region of the country will develop State Organ and Tissue Transplant Organization (SOTTO) in every state/union territory. This was based on the Transplantation of Human Organs and Tissues Rules, 2014.

Each hospital of the country related to transplant activity, either as retrieval or transplant center or both, has to link with NOTTO, through ROTTO/SOTTO as a part of National Networking.

\subsection{What does brain death mean?}

The THOA, 1994 (Central Act 42 of 1994), ${ }^{[11]}$ - definition of death:

"Deceased person" means a person in whom permanent disappearance of all evidence of life occurs,

1. By the reason of brain stem death or

2. In a cardiopulmonary sense at any time after live birth has taken place.

"Brain stem death" means the stage at which all functions of the brain stem have permanently and irreversibly ceased. However, the cause of irreversible coma has to be established, preconditions should be met, and confounding factors are to be ruled out [Figure 1]. ${ }^{[7-10,13]}$

Brain death is commonly caused by: ${ }^{[8-10]}$

- Spontaneous intracranial hemorrhage

- Head injury due to motor vehicle accidents, recreational and industrial accidents, gunshot assault, etc.

- Cerebral anoxia/ischemic injury (cardiac arrest due to asthma, asphyxiation, drug overdose, hanging, drowning, meningitis, carbon monoxide poisoning, or primary cardiac arrest)

- Primary cerebral tumor.

\subsection{How does brain death occur?}

Brain death occurs in response to increased intracranial volume caused by any of the following: ${ }^{[8,9]}$

- $\quad$ Brain swelling

- Blood collections

- Obstruction to cerebrospinal fluid flow (hydrocephalus).

The intracranial pressure (ICP) rises. As the skull is a closed box, blood flow to the brain falls due to rising ICP and finally stops:

The brain dies $\Rightarrow$ Irreversible $\Rightarrow$ Patient dies.

The criteria involved in the diagnosis and declaration of brain death include [Figure 1]:

- Irreversible coma

- Absence of brain stem reflexes, and

- Apnea.

India follows the UK concept of brain stem death, and the THO Act was passed by the Indian Parliament in 1994 which legalized the brain stem death. ${ }^{[11]}$ In 1995, THO rules were laid down which describe brain death certification procedure. 
The state of Maharashtra has passed a resolution making it mandatory to declare and certify "brain death." The Government resolution underlines the responsibilities of hospitals registered under THO Act 1994, that is authorized transplant centers. As the large number of brain death occurs in nontransplant hospitals, it makes for the appropriate authority (Director of Health Services) to register all hospitals in the state that have an operation theater and intensive care unit (ICU) as nontransplant organ retrieval centers (NTORCs). These hospitals are permitted to certify brain death as per procedure and then conduct organ retrieval for therapeutic purposes, but not permitted to perform actual transplantation. Thus, it is mandatory now for all NTORCs and authorized transplant centers in the State to certify and notify the brain death cases to Zonal Transplantation Co-ordination committee. This is a strong step to streamline the procedure for cadaveric organ retrieval and transplantation. ${ }^{[9]}$

The readers are advised to refer to the amendments and adoptions made to the act by their respective states in regard to the structure of the deceased donor organ donation process.

\subsection{Determination of brain death/tests to be done for the diagnosis of brain stem death certification [Figure 2] $]^{[7-10,13,14]}$}

Clinical examination is important for the determination of brain stem death.

\subsubsection{History taking and Physical examination findings that provide a clear etiology of brain dysfunction should be done, including a review of computed tomography/ magnetic resonance imaging films}

The determination of brain death requires the identification of the proximate cause and irreversibility of coma. The evaluation of a potentially irreversible coma should be established with appropriate clinical or neuro-imaging evidences.

\subsubsection{Exclusion of confounding factors that interfere in the clinical diagnosis of brain death [Table 2]}

a. Shock/hypotension - Aim to have systolic blood pressure (SBP) $\geq 90-100 \mathrm{mmHg}$ with vasopressors, if required

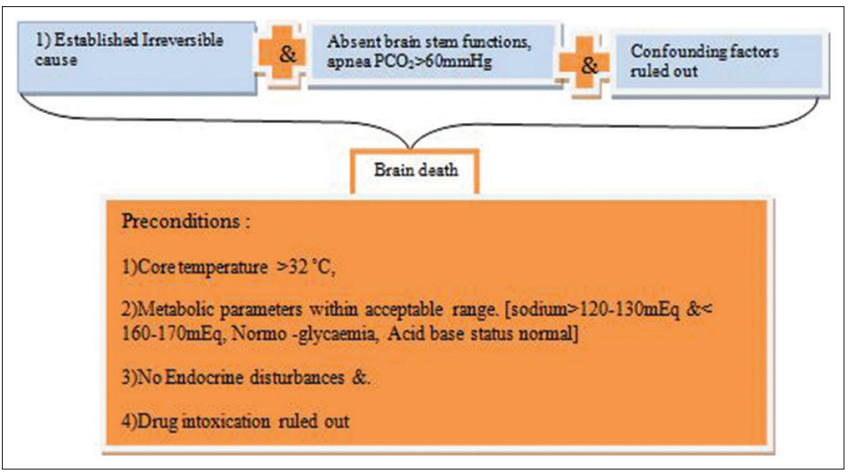

Figure 1: Components of definition of brain death b. Hypothermia - Temperature $<32^{\circ} \mathrm{C}$ (core temperature): Aim for core temperature between $32^{\circ} \mathrm{C}$ and $36^{\circ} \mathrm{C}$ $\left(32^{\circ} \mathrm{C}\right.$ for brain death declaration and $36^{\circ} \mathrm{C}$ for carrying out apnea test)

c. Drugs known to alter neurologic, neuromuscular function, and electroencephalographic testing, such as anesthetic agents, neuro-paralytic drugs, methaqualone, barbiturates, benzodiazepines, high-dose bretylium, amitriptyline, trichloroethylene, and alcohols

Review medication and ICU observation chart for drugs given, and can wait for at least 5 half-lives with normal renal and liver function to exclude a drug effect. Use peripheral nerve stimulator for train-of-four Response (TOF) to rule out muscle relaxant effect. This is particularly important where patients are referred from periphery to tertiary care center

d. Brain stem encephalitis - Review history and imaging

e. Guillain-Barre' syndrome - Review history and imaging

f. Encephalopathy associated with hepatic failure, uremia, and hyperosmolar coma - Review history and imaging

g. Severe hypophosphatemia - Check phosphate levels if in doubt

h. Neurotoxic snake envenomation - Review history.

\section{Table 2: Confounding factors that interfere in clinical diagnosis of brain death}

Shock/hypotension
Hypothermia temperature $<32^{\circ} \mathrm{C}$ (core temperature)
Neurotoxic snake envenomation
Brain stem encephalitis
Guillain-Barre' syndrome
Encephalopathy
Severe hypophosphatemia

Drugs known to alter neurologic, neuromuscular function, and electroencephalographic testing, such as anesthetic agents, neuro-paralytic drugs

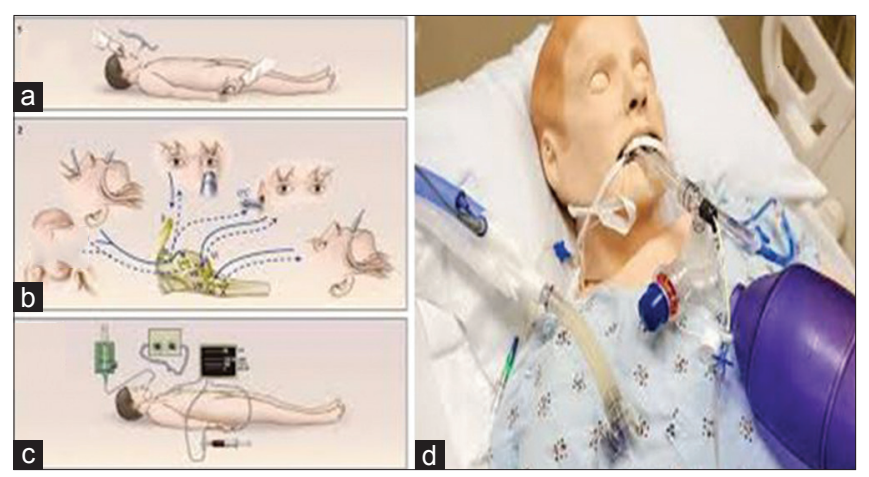

Figure 2: (a) Sites for painful stimulus: supra-orbital region, finger nail bed (b) Tests carried for nerve examination, corneal reflex (afferent $\mathrm{V}$ efferent VII), pupils dilated (II and III), caloric test (efferent VIII and efferent VI), cough reflex (afferent IX and efferent X), (c) Apnea test, (d) Apnea test with the help of positive end-expiratory pressure valve 


\subsubsection{Performance of a complete neurological examination [Figure 2]}

I. Examination of the patient for the response to noxious stimuli, administered through a cranial nerve pathway. Spinal reflexes may be present. Suggested sites for noxious stimuli are supraorbital grove bilaterally and trapezius squeeze bilaterally

II. Absent pupillary reflex to direct and consensual light (cranial nerve II and III); pupils need not be equal or dilated. Conditions interfering in the pupillary reflex are orbital trauma, head injury, cataracts, and medications such as high-dose dopamine, glutethimide, scopolamine, atropine, bretylium, or monoamine oxidase inhibitors [Figure 2b]

III. Absent corneal reflex (cranial nerve $\mathrm{V}$ and VII), oculocephalic, cough, and gag reflexes (cranial nerve IX and $\mathrm{X}$ ). The corneal reflex may be altered as a result of facial weakness [Figure 2b]

IV. Cold caloric test/absent oculovestibular reflex (cranial nerve VIII, III, and VI): The external auditory canal should be clear of cerumen, and tympanic membranes should be intact. Elevate the patient's head by $30^{\circ}$. Irrigate $20-50 \mathrm{ml}$ of ice water into the external auditory canal and over the tympanic membrane using a soft irrigation cannula. One should look for eye ball movement for which upper eyelids need to be retracted. Allow $1 \mathrm{~min}$ response time after injection/irrigation of fluid and at least $5 \mathrm{~min}$ between testing on each side. No eye ball movements will be seen in brain-dead patients

Labyrinthine injury or disease, anticholinergics, anticonvulsants, tricyclic antidepressants, and some sedatives may alter response [Figure 2b].

\subsubsection{Absent respiratory efforts in the presence of hypercarbia: Apnea test}

I. The following prerequisites must be met before carrying out the apnea test ${ }^{[13,15]}$

- $\quad$ Core temperature $\geq 36.5^{\circ} \mathrm{C}$ or $97.7^{\circ} \mathrm{F}$

- Euvolemia or positive fluid balance in the previous $6 \mathrm{~h}$

- Normal $\mathrm{PCO}_{2}$ or arterial $\mathrm{PCO}_{2} \geq 40 \mathrm{mmHg}$

- Normal $\mathrm{PO}_{2}$ - Preoxygenation for $15 \mathrm{~min}$ with $100 \%$ oxygen before carrying out the apnea test, try to achieve an arterial $\mathrm{PO}_{2} \geq 200 \mathrm{mmHg}$ for safely conducting the test.

\section{Steps for apnea test [Figure $2 \mathrm{~b}$ and c]}

Preoxygenate the patient with $100 \% \mathrm{O}_{2}$ for $10-15 \mathrm{~min}$ (to ensure denitrogenation of lungs) and do a baseline arterial blood gas analysis

- Connect a pulse oximetry and disconnect the ventilator

- Deliver 4-6 1/min of $\mathrm{O}_{2}$ through endotracheal tube into the trachea using a soft catheter

- Look closely for any respiratory movements (abdominal or chest excursions that produce adequate tidal volumes)
- Measure arterial $\mathrm{PO}_{2}, \mathrm{PCO}_{2}$, and $\mathrm{pH}$ after approximately 8-10 min later (for every minute of apnea, $\mathrm{PaCO}_{2}$ rises by approximately $3 \mathrm{mmHg}$ )

- If respiratory movements are observed, the apnea test result is negative (i.e., it does not support the clinical diagnosis of brain death)

- Connect the ventilator, if during testing

- $\quad$ The SBP becomes $<90 \mathrm{mmHg}$ (or below age-appropriate thresholds in children $<18$ years of age)

- Or the pulse oximetry indicates significant oxygen desaturation

- Or cardiac arrhythmias develop.

III. Interpretation

- If respiratory movements are absent and arterial $\mathrm{PCO}_{2}$ is $\geq 60 \mathrm{mmHg}$ (option: $20 \mathrm{mmHg}$ increase in $\mathrm{PCO}_{2}$ over a baseline normal $\mathrm{PCO}_{2}$ ), the apnea test result is positive (i.e. it supports the diagnosis of brain death) ${ }^{[13,15]}$

- If $\mathrm{PCO}_{2}$ is $<60 \mathrm{mmHg}$ and $\mathrm{PCO}_{2}$ increase is $<20 \mathrm{mmHg}$ over baseline, the result is indeterminate and a confirmatory test can be considered or apnea test can be repeated

- When appropriate, a $10 \mathrm{~min}$ apnea test can be repeated after preoxygenation for 15 min with an $\mathrm{FiO}_{2}$ of 1.0 and normalization of patients' $\mathrm{PaCO}_{2}$ of $40 \mathrm{mmHg}^{[13,15]}$

IV. Queries about apnea test [Table 3]

a. When should the apnea test be done?

Determination of brain death should be thorough and meticulous.

A formal evaluation of the brain stem reflexes is undertaken after the above-mentioned observation period. After the first clinical examination, the patient should be observed for a defined period of time for clinical manifestations that are consistent with the diagnosis of brain death. Most experts agree that a 6-h observation period is sufficient and reasonable in adults and children over the age of 2 years (Grade 1A). ${ }^{[1,14-16]}$

Pallis and Harley ${ }^{[17]}$ stress the importance of appropriate duration of observation that must be provided to ensure irreversibility of the pathological processes. Suggested observation period is mentioned in Table 4.

b. Is consent necessary for apnea test?

- Consent is not necessary for carrying out apnea test (though an assent of family, informing them about the test been done, would be appreciated) (Grade 2B).

\section{Table 3: Queries about apnea test}

\footnotetext{
When should the apnea test done?

Who should do it?

Is consent necessary of apnea test?

Troubleshooting for apnea test
} 
c. Troubleshooting during performance of apnea test [Figures 3 and 4]

1. Patient's SBP $\leq 100 \mathrm{mmHg}$ : Vasopressors, inotropes, and fluid boluses need to be administered to keep the BP above the target. The apnea test is aborted if SBP is $\leq 90 \mathrm{mmHg}$ and the test needs to be repeated after stabilization. ${ }^{[1,13,15]}$

2. Oxygen saturation not maintained during apnea testing:

The apnea testing is terminated if the saturation is $\leq 85 \%$ for more than $30 \mathrm{~s}$. The test can be retried with T-piece and continuous positive airway pressure of $10 \mathrm{~cm} \mathrm{H}_{2} \mathrm{O}$ or more and oxygen flow of $12.0 \mathrm{~L} / \mathrm{min}$ (Grade $2 \mathrm{~B})$. Reducing the positive end-expiratory pressure (PEEP) to $5 \mathrm{~cm} \mathrm{H}_{2} \mathrm{O}$ prior to disconnection from the ventilator for apnea testing can predict the tolerance to apnea. With the help of PEEP valve, one can give PEEP up to $25 \mathrm{~cm} \mathrm{H}_{2} \mathrm{O}$ [Figure 4].

3. Patient is hypothermic $<35^{\circ} \mathrm{C}$ : Guidelines for apnea testing are not valid and need to be repeated after correction of hypothermia. ${ }^{[1]}$

4. Patient repeatedly desaturates or becomes hypotensive during apnea testing: One should consider ancillary tests for confirming brain death. Ancillary tests for confirming brain death such as electroencephalography (EEG), cerebral angiography, transcranial Doppler, and scintigraphy may be considered if available.

\begin{tabular}{lc}
\hline Table 4: Examples of observation periods in hours before \\
testing for brain death \\
$\begin{array}{l}\text { Apneic coma after } \\
\quad \text { Major neurosurgery }\end{array}$ & $>4 \mathrm{~h}$ \\
$\quad$ Confirmed aneurysm & $>6 \mathrm{~h}$ \\
$\begin{array}{l}\text { Head injury (no secondary brain damage from hematoma, } \\
\text { shock, or brain hypoxia) }\end{array}$ & $>6 \mathrm{~h}$ \\
$\begin{array}{l}\text { Spontaneous intracerebral bleed } \\
\text { Brain hypoxia (drowning, cardiac arrest) }\end{array}$ & $>24 \mathrm{~h}$ \\
$\begin{array}{l}\text { Any of the above (with suspicion of drug intoxication but no } \\
\text { screening facilities) }\end{array}$ & $50-100 \mathrm{~h}$ \\
\hline
\end{tabular}

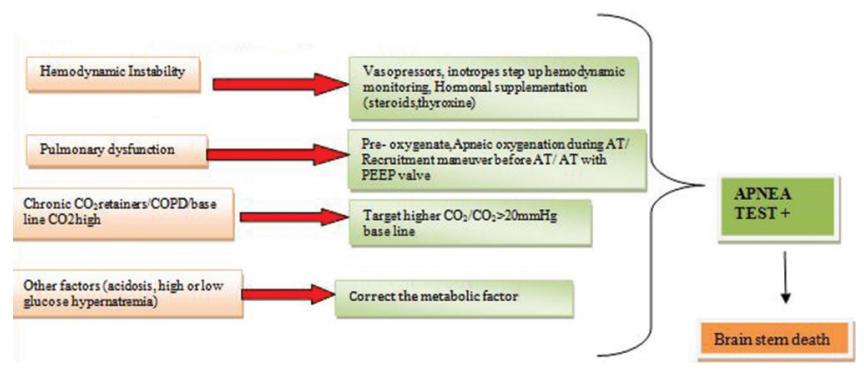

Figure 3: Troubleshooting in apnea testing
These do not replace clinical assessment and it is notable that THOA in India does not mandate the use of ancillary tests [section 1.7] (Grade 1A). ${ }^{[13,15]}$

5. Baseline $\mathrm{PaCO}_{2} \geq 40 \mathrm{mmHg}$ or $\leq 35 \mathrm{mmHg}$ : A rise of $\geq 20 \mathrm{mmHg}$ above baseline can be considered a positive apnea test in patients with elevated baseline $\mathrm{PaCO}_{2}$.

Reducing the frequency of ventilation to allow a $\mathrm{PaCO}_{2}$ in the recommended range should be considered prior to testing of apnea (Grade 2B). ${ }^{[13,15]}$

\subsection{Observations which are compatible and incompatible with brain stem death}

Compatible:

- Spinal reflexes

- Sweating, blushing, tachycardia

- Normotension without pharmacologic support

- Absence of diabetes insipidus (DI).

Incompatible:

- Decerebrate or decorticate posturing

- Extensor or flexor motor responses to painful stimuli

- Seizures.

Reason for spinal reflexes according to one hypothesis: the reflex movements represent hypoxia- and hypercapnia-induced activity of cervical cord neurons. Alternatively, they might be due to disinhibition of movement generators of the spinal cord. Another hypothesis is that mechanical compression/decompression of the spinal root or cervical spinal cord by neck flexion/extension can generate movement. ${ }^{[1,13]}$

\subsection{Ancillary tests}

When the full clinical examination, including both assessments of brain stem reflexes and the apnea test, is conclusively performed, no additional testing is required to determine brain death (Grade 1A) ${ }^{[1,9,14]}$ Confirmatory tests such as EEG, cerebral angiography, transcranial Doppler, and radionuclide scan are not mandatory. As per the TOHA, the ancillary tests are not mentioned at all, hence its legal acceptability is challenging. ${ }^{[10,11]}$
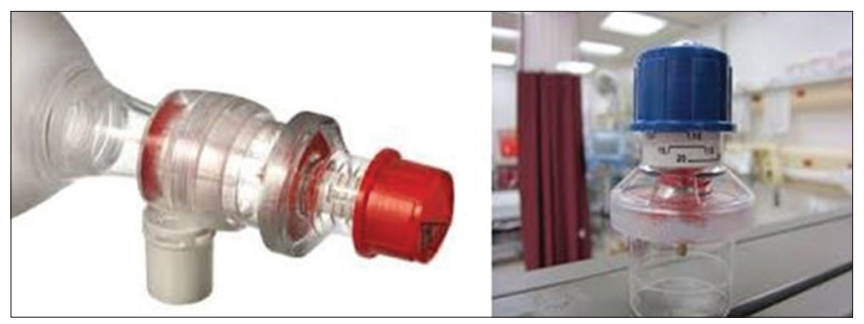

Figure 4: Positive end-expiratory pressure valve 
Indications for ancillary tests are:

1. Patients with cranial or cervical injuries, cardiovascular instability ${ }^{[16]}$

2. Severe facial trauma, otorrhagia, eye agenesis ${ }^{[16]}$

3. Preclude the performance of a portion of the clinical examination, reassure family members and medical staff $^{[14]}$

4. A panel of doctors who are in doubt or disagreement of the diagnosis. ${ }^{[18]}$

\section{Legal Aspects in India for Certification of Brain Death [Table 5]}

2.1. Who can certify and how many doctors required? ${ }^{[1,11,14,18]}$ Registered medical practitioners with appropriate authority should do apnea test and can certify brain stem death. ${ }^{[1]}$ The diagnosis of brain death is established and recorded by two doctors not belonging to the retrieval and transplantation teams (Grade 1A). ${ }^{[1,11,14,16,18]}$ Out of the two doctors, one must be a specialist in neurology (Grade 1A). The order of examination is irrelevant, i.e., it does not matter whether the neurologist performs the first or the second examination. ${ }^{[16]}$

For certification of brainstem death, it requires a panel of four doctors.

1. Doctor in charge of the patient

2. The doctor in charge of the hospital where the patient was treated

3. An independent specialist of unspecified specialty (physicians, surgeons, or intensivists) nominated from the panel of names approved by the appropriate authority

4. Neurologist or neurosurgeon.

Form 10 should be filled and signed by the medical experts certifying brain stem death.

Amendments in the THOA (2011) and THAO rules 2014 have allowed selection of a surgeon/physician and an anesthetist/intensivist, in the event of the nonavailability of neurosurgeon/neurologist.

\subsection{How many times the clinical examination and test are needed to be done and what is the interval between two tests? ${ }^{[11,14]}$}

Clinical examination and apnea test need to be done 2 times after an interval of $6 \mathrm{~h}$. After the second test, the team should start counseling the family regarding organ donation.

The time of death is the end of the second apnea test.

Table 5: Legal aspects for certification of brain death

Who can certify?

How many doctors required?

How many times test needed?

What is the observation interval between the second set tests?

\subsection{What needs to be included in medical record} documentation? ${ }^{[14]}$

All phases of the determination of brain death should be clearly documented in the medical record:

- Etiology and irreversibility of coma/unresponsiveness

- Absence of motor response to pain

- Absence of brain stem reflexes during two separate examinations separated by at least $6 \mathrm{~h}$

- $\quad$ Absence of respiration with $\mathrm{pCO}_{2} \geq 60 \mathrm{mmHg}$

- Justification for, and result of, confirmatory tests if used.

All the four doctors (members from Panel of The Board of Medical Experts) should sign tests done to document the absence of brain stem function, namely, pupillary reflex, doll's head eye movement, corneal reflex (both sides), gag reflex, cough (tracheal), eye movements on caloric testing bilaterally, absence of motor response in any cranial nerve distribution, and apnea test. ${ }^{[18]}$

In India, Form 10 is necessary for brain death certification. ${ }^{[1]}$

\section{Communication Platform}

The medical expert registered with appropriate authority need to have a dialog with the relatives about carrying out the tests for brain stem death. Given the situation and delicate sentiments of family/caregivers, the person responsible for breaking news to family/caregivers about patient's brain stem death should be sensitive to the responses and feelings of the family members/caregivers.

The ICU physician should communicate the confirmation of brain stem death to transplant coordinator who in turn can communicate to family and make request for the organ donation (Grade 1A). Simultaneously, the administrators of the hospital should be communicated to stop the further billing once diagnosis of brain stem death is confirmed and family has consented for the organ donation.

\subsection{The process of consent for organ and tissue donation involves ${ }^{[10,11,14]}$}

1. The deceased

2. Next of kin

3. Coroners' consent (medicolegal cases).

The deceased

The deceased wishes must be ascertained through hospital staff/relatives/donor coordinator (driving license, etc., wherein the provision for donation may be incorporated after notification of the THOA rules). In India, even if the deceased wishes are known, the next of kin need to formally consent and sign the consent form. ${ }^{[11]}$

The NOTTO Organ Donor Register is a computerized database which records the wishes of people who have pledged for organ and tissue donation and decided that, after their death, they want to leave a legacy of life for others. There are many hospitals and organizations those are also maintaining the list 
of persons who have pledged organ donation with them, all this will be a part of NOTTO website for National Register.

\section{Next of kin consent}

Hospital staff need to speak with the relatives about organ donation on behalf of the deceased.

The surrogate decision-making authority includes:

1. Spouse

2. Son or daughter (18 years or over)

3. Parent.

In case of dispute in the family or a difference of opinion in the family, ample amount of time should be given to the family to discuss, settle, and give a final decision.

Form 8 need to be filled and signed to record the status of the cum consent by near relative or lawful possessor of brain stem dead person.

It is necessary to inform police about organ donation consent to the station house officer or superintendent of police or deputy inspector general, if it is a documented medicolegal case.

Once the consent for organ donation is achieved, the cost for maintenance of cadaver or retrieval or transportation or preservation of organs or tissues, their transportation, and preservation may be borne by the recipient or institution or government or nongovernmental organization but not by the donor family (Grade 1A).

\subsection{Areas of controversy}

Data protection and confidentiality of recipients has to be maintained. Donor's family cannot have access to recipient's name.

As mentioned earlier, the police need to be informed about organ donation consent in case of medicolegal cases. A copy of consent should also be sent to the designated postmortem doctor. It shall be ensured that by retrieving organs the determination of the cause of death is not jeopardized. The medical report in respect of the organs or tissues retrieved and prepared by retrieving doctors shall be taken on record in postmortem notes.

\section{Medical Suitability for Organ Donation}

The patient must be medically suitable to donate organs for transplantation. Criteria for suitability change over time and vary according to recipient circumstances. Early determination of the suitability for transplantation of specific organs facilitates the development of focused medical management strategies (e.g., more aggressive fluid therapy when lung donation is contraindicated).

\subsection{Exclusion criteria for organ donation}

1. Infection with human immunodeficiency virus, human T-cell leukemia-lymphoma virus
2. Systemic viral infections (measles, rabies, adenovirus, parvovirus) and herpetic meningoencephalitis ${ }^{[7,9,14,16]}$

3. Active malignant disease or a history of malignancy that poses a high risk for transmission irrespective of the apparent disease-free period (e.g. melanoma, choriocarcinoma).

Bacteremia or fungemia is not an absolute contraindication to donation. ${ }^{[7]}$

Acute organ dysfunction, in particular acute renal failure, in a potential donor with prior renal function is not a contraindication to donation.

\subsection{What is the accepted age range for multiple organ and tissue donors?}

There is no maximum age for donation; however, comorbidities that develop together with aging make donation less acceptable. Marginal or expanded criteria donors are those presenting clinical conditions that might reduce graft survival, impair its function, or are at a high risk of disease transmission (Grade 1A) [Table 6]. ${ }^{[16]}$

The use of marginal donors is only justified when the life expectancy after transplantation is higher compared with conventional clinical treatment. ${ }^{[12]}$

\section{Recommendation}

For recipients under 45 years old, the ideal age of deceased donors is depicted in Table 6.

Older persons (e.g., up to 80 years of age) (Grade 2B) ${ }^{[16]}$ and those with a history of hypertension and diabetes mellitus need to be worked up for individual organ function such as albumin: creatinine ratio for kidney function.

\section{Care of Organ Donor}

Intensive care specialists assist critically ill patients to recover from illness and lead a good quality of life. Brain stem death usually results in complex multiple organ failure. In such cases, the decision to stop or remove specific brain-related intensive treatments needs to be taken. However, extra-cranial physiological support may be continued till the determination of brain death or very severe irreversible brain damage. Appropriate management of donor before and after brain death

\begin{tabular}{lll}
\hline \multicolumn{2}{l}{ Table 6: Age limit for deceased organ donor } \\
\hline $\begin{array}{l}\text { Deceased donor } \\
\text { organs }\end{array}$ & Age limit & $\begin{array}{l}\text { Grading of } \\
\text { recommendation }\end{array}$ \\
\hline Kidneys & Up to 60 years old & Grade 2B \\
Liver & Up to 60 years old & \\
Kidney-pancreas & $18-45$ years old & \\
Pancreas & 7 days to 50 years old & \\
Heart & 45 years old & \\
Lungs & $60-65$ years old & \\
\hline
\end{tabular}


may result in increasing the frequency and improving quality of donor organs. ${ }^{[3,7]}$

All health-care personnel and ICU attendants should have a responsible and professional behavior at the bedside of the patient. Medical procedures and investigations should only be done if they are required to facilitate the donation procedure.

\subsection{Physiological and metabolic changes during brain death [Figure 5]}

\subsubsection{Cardiovascular system}

Hemodynamic instability and cardiac dysfunctions are always encountered in patients after brain death. ${ }^{[19,20]}$ Myocardial dysfunction often occurs as a result of severe brain injury. ${ }^{[21-23]}$ The exacerbated stress response, i.e. "sympathetic storm,"results in hypertension, tachycardia, and arrhythmias. Though usually of short duration, it may lead to cardiac dysfunction, cardiac ischemia, myocardial and conduction system necrosis. ${ }^{[7,9,21,22]}$ Further, spinal cord ischemia is followed by deactivation of sympathetic storm and loss of cardiac stimulation. This leads to vasodilatation and cardiac dysfunction, clinically presenting as hemodynamic instability in potential donor. Other factors contributing to hypotension are diuretics (mannitol), hyperglycemia-induced osmotic diuresis, DI, hypothermic "cold" diuresis, inadequate fluid resuscitation and decreased oncotic pressure after crystalloid resuscitation, ongoing blood loss, rewarming of patient, relative adrenal insufficiency as a result of trauma, and critical illness. ${ }^{[7]}$

\subsubsection{Diabetes insipidus}

DI is a common problem in brain-dead patients. It occurs in about $80 \%$ of the patients with brain death. However, absence of DI does not mean that the patient is not brain dead. DI results from the deficiency of anti-diuretic hormone due to loss of posterior pituitary function ${ }^{[2]}$ leading to polyuria. In patients with urine output more than $200 \mathrm{ml} / \mathrm{h}$ for consecutive $2 \mathrm{~h}$,

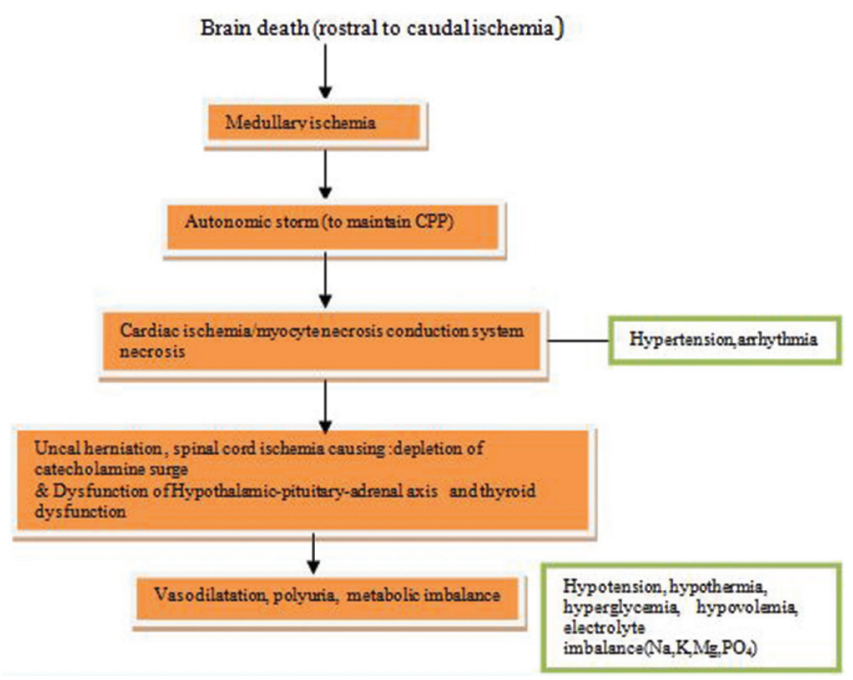

Figure 5: Events in brain-dead patients diagnosis of DI should be suspected. If left untreated, DI often leads to hypovolemia and hypernatremia. Hypernatremia may adversely affect the outcomes for renal and liver transplants (Grade 2A). ${ }^{[22-25]}$

\subsubsection{Hypothermia}

Brain death results in hypothermia due to loss of thermoregulation, reduced metabolic rate, excessive heat loss, and loss of protective mechanisms such as vasoconstriction or shivering. ${ }^{[3]}$ Exposure and administration of cold fluids may further increase the risk of hypothermia. Hypothermia is best avoided or prevented rather than treated. Once hypothermia sets in, it is difficult to warm patients and it has direct effect on cardiac function, arrhythmias, coagulation cascade, and oxygen delivery to tissues.

\subsubsection{Hormonal dysfunction}

Circulating triiodothyronine $\left(\mathrm{T}_{3}\right)$ may be low in patients with brain death. ${ }^{[26]}$ Thyroid hormone deficiency along with cortisol deficiency may contribute to hemodynamic instability. ${ }^{[27]}$ The data also suggest that function of anterior pituitary is partially preserved, with normal levels of cortisol and thyroid hormone, or low thyroid hormone with normal/raised thyroid-stimulating hormone levels consistent with sick euthyroid syndrome. ${ }^{[28]}$ Hyperglycemia is common in brain stem death patients because of reduced insulin concentrations and insulin resistance. ${ }^{[3]}$

\subsubsection{Anemia, coagulopathy, and immunological changes} Traumatic bleeding commonly results in anemia. Furthermore, coagulopathy and fluid administration may cause exacerbation of anemia. Significant rise in pro-inflammatory cytokines such as interleukin-6 has been observed in brain-dead potential organ donors which could be one of the causes of coagulopathy. ${ }^{[28,29]}$ The other possible causes include dilutional coagulopathy due to fluid administration, and it may be worsened by hypothermia. ${ }^{[29]}$

\section{Multisystem Management of Multiorgan DONOR}

\subsection{General care ${ }^{[30]}$}

General measures of infection control should be applied. These include:

- Hand hygiene - As per standard medical/nursing care (Grade 1A)

- Frequent turning of patient for decubitus ulcer prophylaxis, skin care, dressing changes, urinary and intravascular catheter care must be meticulous to minimize the risk of infection (Grade 1A)

- Bronchial toilet - Improves elimination of secretions and therefore improves chances of lung donation (Grade 2B)

- $\quad$ Eye care - Care to ensure no corneal abrasions or ulcers and improves the chance of corneal donation. Reduces heat loss and actively warms if necessary to maintain core temperature of $35^{\circ} \mathrm{C}$ (Grade 1B) 
- A nasogastric tube must be inserted for gastric decompression and prevention of aspiration (Grade 1B)

- Arterial and central venous lines should be inserted preferably into the upper extremities because femoral line readings can become inaccurate during surgical procedure for organ procurement (Grade 2B).

\subsection{Monitoring ${ }^{[30]}$}

Monitoring is a crucial part of the medical management of potential organ donor. Routine monitoring includes ECG, BP, pulse oximetry, core temperature, hourly urine output, and central venous pressure (Grade 1A). Bedside echocardiography for the assessment of fluid deficit (Grade 1A), and use of Swan-Ganz catheter/cardiac output monitors should be reserved for unstable donors, who have persistent acidosis with the evidence of tissue hypoperfusion (Grade 2B).

\subsection{Laboratory ${ }^{[30]}$}

Arterial blood gas, lactate, electrolytes, and blood sugar levels need to be monitored every 2-4 hourly (Grade 1A). ${ }^{[9]}$ Parameters such as hemoglobin, hematocrit, complete blood count, blood glucose, urine analysis, blood urea nitrogen, serum creatinine, serum electrolytes, liver function tests, coagulation profile, and microbiological screening for hepatitis B, C, hepatitis B core antigen, HIV, and IgM and IgG for cytomegalovirus are necessary (Grade 1A).

Mandatory investigations include blood group, HIV antibody, hepatitis B surface antigen, and hepatitis $C$ virus antibody (Grade 1A).

However, risk of transmission of infection may still remain.

Cultures of blood and urine may be required, if there is evidence of infection or if the patient is hospitalized for more than $72 \mathrm{~h}$ (Grade 2B). Some additional tests may be required for multiorgan donors, for example, echocardiography for heart and bronchoscopy for lung transplantation.

\section{Goals for Maintenance of Potential Organ Donor [Figure 6] ${ }^{[3,30]}$}

One should aim to maintain body temperature, ensure adequate oxygenation, circulating volume, cardiovascular stability, and adequate urine output.

A simple method to maintain potential donor is "rule of 100" (Grade 1B) [Table 7]. ${ }^{[1]}$

The medical management of organ donor can be broadly divided into:

- Management of hemodynamics

- Management of metabolic derangement

- Temperature management

- Management of respiration and hematological parameters

- Nutrition management.

The treatment aspects of these parameters are summarized below.

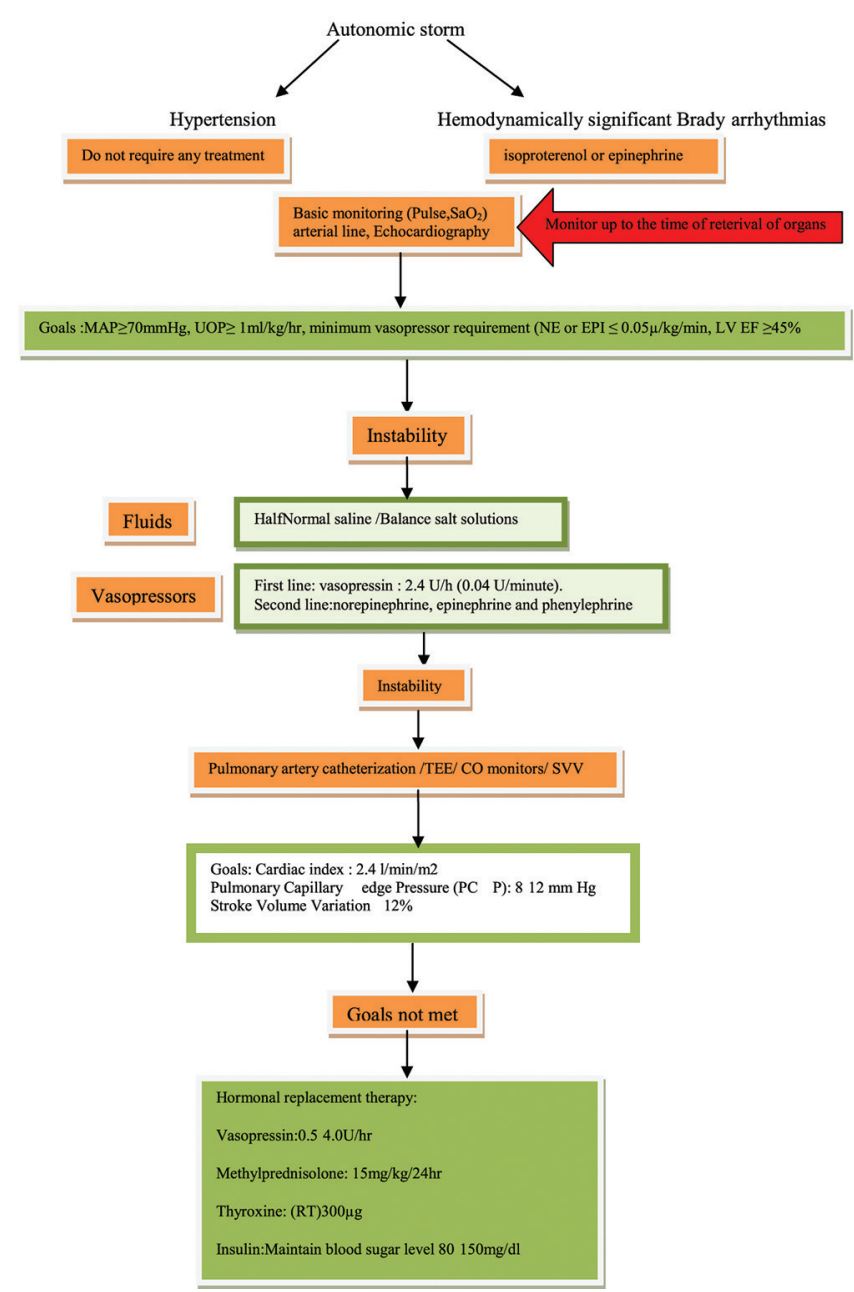

Figure 6: Goals for maintenance of potential donor

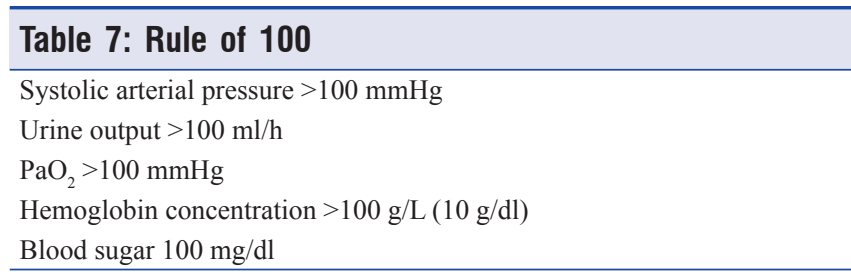

\subsection{Management of hemodynamics}

Goals for management of hemodynamic status of the donor are as follows: ${ }^{[7,30]}$

1. To maintain normovolemia and BP

2. Optimize cardiac output so as to maintain perfusion pressure of all organs with the use of the least amount of vasoactive support.

\subsubsection{Hypertension}

Due to the transient nature of autonomic storm, antihypertensives are usually not required. If needed, short-acting antihypertensives such as esmolol, sodium nitroprusside, hydralazine, labetalol, or nitroglycerine should 
be used (Grade 1B). Antihypertensive is not required for a long time.

\subsubsection{Hypovolemia}

Intravenous fluid administration is required for the management of hypovolemia. However, the decision for selection of fluid depends on serum electrolytes, sugar level, hemodynamic of the patient, estimated volume deficiency, and polyuria from DI. Organs such as lungs may require minimal fluid for optimizing function. ${ }^{[31]}$ The suitable organs for transplantation should be identified in advance to plan focused medical management of fluid replacement. Significant positive fluid balance is associated with progressive pulmonary dysfunction. ${ }^{[32]}$

One should check for signs of continuing hemorrhage (external, GI, urinary, abdominal, etc.) (Grade 1A).

Discontinue medications that may contribute to hypotension (e.g., antihypertensives, beta-blockers) (Grade 1A).

Three management strategies are commonly adopted, and treatment is escalated depending on the clinical response. These strategies are: ${ }^{[7]}$

A. Volume expansion

B. Vasopressors and inotropes

C. Hormonal replacement.

Volume expansion/preload ${ }^{[7]}$

Which fluid?

- Crystalloids with balanced salt content so as to avoid hypernatremia (concurrent DI) and hyperchloremic acidosis (increases renal vascular resistance, confounds base excess) when used as resuscitation target (Grade 1A). Administration of excessive intravenous fluids containing $5 \%$ dextrose may further complicate hyperglycemia and hypothermia ${ }^{[32-34]}$

- Avoid colloids. Hydroxyethyl starches are contraindicated in organ donors because they can damage renal epithelial cells and cause early graft dysfunction in the transplanted kidneys (Grade 1A) ${ }^{[7,35]}$

- Albumin solutions $(20 \%, 4 \%)$ may be considered to reduce the amount of volume given, although usually only moderately effective (Grade 2B). The high sodium content of albumin-based solutions needs to be taken into account

- The most commonly used fluids are Ringer's lactate, Plasmalyte-A, Ringer's acetate, and half normal saline (Grade 1A) ${ }^{[1,7,33,34]}$

- Packed red cells should be transfused to achieve a hematocrit of $30 \%$ to maintain oxygen delivery (Grade 2A). ${ }^{[7]}$

Monitoring ${ }^{[7]}$

Central venous pressure measurement alone is a poor guide for directing resuscitation, and alternative techniques can be used to assess effective fluid administration responsiveness (Grade 1A).

- $\quad$ Repeat bedside echocardiography (Grade 2A)
- $\quad$ Pulse pressure variation is a method that has been used to determine optimal fluid status (Grade 2B)

- Urine output $1-3 \mathrm{ml} / \mathrm{kg} / \mathrm{h}$ (in the absence of polyuria due to DI or diuretics) (Grade 1A)

- $\quad$ Cardiac index $>2.5$ (note - high cardiac output state due to vasodilatory shock may be a confounder) (Grade 2B)

- Central venous oxygen saturation $>70 \%$ (note - low basal metabolism due to brain death may be a confounder) (Grade 2B).

\section{Vasopressors}

An adequate perfusion pressure should be maintained. The targets for SBP and mean arterial pressure should be $>100 \mathrm{mmHg}$ and $>70 \mathrm{mmHg}$, respectively (Grade 1A). ${ }^{[3]}$

Vasopressor medicines may be required frequently to support mean arterial pressure once hypovolemia has been excluded/corrected. Vasopressin in pressor dose (1-2 U/h) plays an important role in stabilizing the hemodynamic of brain-dead patients (Grade 1A). ${ }^{[36,37]}$ Vasopressin up to 2.4 units/h may reduce the requirement of other ionotropes. ${ }^{[3]}$ The utility of low-dose vasopressin to treat DI, aid restoration of vascular tone, and reduce epinephrine requirement was first identified in brain-dead patients receiving long-term support. When the loss of vascular tone is preventing the achievement of donor goals, low-dose vasopressin may allow reduction or elimination of catecholamine use, as in other ICU patients. ${ }^{[1]}$ Canadian guidelines recommend vasopressin as the first-choice vasopressor for donor resuscitation. ${ }^{[36,37]}$

Norepinephrine is also commonly used for this purpose (Grade 1A) ${ }^{[34]}$ Norepinephrine is required in higher doses compared to epinephrine. As far as possible, high doses of norepinephrine $>0.05 \mathrm{mg} / \mathrm{kg} / \mathrm{min}$ should be avoided (Grade 2B).

A study of brain-dead patients has shown that pressor dose of vasopressin and epinephrine combination effectively increases the mean arterial BP with increase in total peripheral resistance index and cardiac index. Dopamine can be used as well, but has an increased incidence of arrhythmias. ${ }^{[34]}$ Intravenous fluids and inotropes/vasopressors (dopamine, dobutamine, epinephrine, vasopressin, and norepinephrine) should be administered based on the central venous pressure and bedside two-dimensional echocardiography (Recommendation Grade 1B).

\section{Hormonal replacement}

There are no clear recommendations regarding $\mathrm{T}_{3}$ administration for improving hemodynamic status and cardiac function in potential donors and also the results are not clear. ${ }^{[1,7]}$ Moreover, $\mathrm{T}_{3}$ is not easily available in India. Thyroxine $\left(\mathrm{T}_{4}\right) 300-400 \mathrm{mcg}$ through nasogastric route can be given in hemodynamically unstable patients, but absorption and clinical effect are not proven (Grade 2B).

\subsubsection{Arrhythmias}

Efforts should be made to prevent arrhythmia or promptly treat it, because of problems associated with them. It is more 
commonly seen in cases of longer lag between brain death and organ removal.

\section{Prevention of arrhythmia}

Electrolytes, BP, fluid volume, and body temperature should be carefully monitored and maintained within normal range to reduce the risk of development of cardiac arrhythmia (Grade 1A).

\section{Treatment of tachyarrhythmia}

If arrhythmia occurs, it can be treated with standard therapy such as amiodarone or cardioversion (Grade 1B).

Atropine is not useful in the management of bradycardia whereas adrenaline, isoprenaline, or pacing may be effective (Grade 2B). ${ }^{[38]}$

\subsection{Management of hormonal and metabolic derangement} 7.2.1. Hormonal resuscitation

Some studies have recommended its use in persistent hemodynamic instability and/or when ejection fraction is $<45 \%$ on echocardiography and when heart donation is planned. ${ }^{[7,28,39]}$ However, there is no strong evidence for use of hormonal resuscitation. ${ }^{[7,28,39]}$ There is limited data on the benefit of hormone administration in humans. Small studies with thyroid hormone have not shown benefit on hemodynamic status in brain-dead patients..$^{[3,7,26,40]}$ Thus, the evidence on anterior pituitary or thyroid dysfunction in brain death is conflicting.

In patients in whom lung transplant is a distinct possibility, use of methylprednisolone has shown some benefits. ${ }^{[41]}$ The results of a retrospective analysis of 118 consecutive organ donors, of which eighty received high-dose methylprednisolone during donor management, demonstrated improved oxygenation at organ recovery. With high-dose steroid treatment, significant increase in the number of lung utilization was seen possibly because of the anti-inflammatory benefits of steroid.

We suggest (Grade 1B): ${ }^{[3,7,34,38]}$

a. Vasopressin $1 \mathrm{U}$ bolus followed by an infusion of $0.5-4.0$ $\mathrm{U} / \mathrm{h}$ (desmopressin intranasal has a selective action on the $\mathrm{V} 2$ receptors and a half-life varying from 6 to $20 \mathrm{~h}$ )

b. Methylprednisolone: $15 \mathrm{mg} / \mathrm{kg}$ immediately after the diagnosis of brain death and $24^{\text {th }}$ hourly thereafter. Another option is $250 \mathrm{mg}$ followed by $100 \mathrm{mg} / \mathrm{h}$ till the organ retrieval

c. Insulin infusion to maintain blood glucose between 80 and $150 \mathrm{mg}$

d. $\mathrm{T}_{4} 20 \mathrm{mcg}$ bolus followed by infusions of $10 \mathrm{mcg} / \mathrm{h} . \mathrm{T}_{3}$ given as a 4-mcg bolus followed by an infusion of $3 \mathrm{mcg} / \mathrm{h}$. $\mathrm{T}_{4}$ improves hemodynamics and prevents cardiovascular collapse in hemodynamically unstable organ donors. However, intravenous $\mathrm{T}_{3}$ is generally not available. So, $\mathrm{T}_{4}$ oral $300-400 \mathrm{mcg} / 8$ hourly is suggested instead of $\mathrm{T}_{3}$ (NOTTO).

\begin{tabular}{|c|c|}
\hline \multicolumn{2}{|c|}{$\begin{array}{l}\text { Table 8: Dose of desmopressin and vasopressin with } \\
\text { acceptable urine output }\end{array}$} \\
\hline Acceptable urine output & $30-200 \mathrm{ml} / \mathrm{h}$ \\
\hline \multicolumn{2}{|l|}{ Dose } \\
\hline Desmopressin & $10 \mathrm{mcg} /$ nasal puff; $1-2$ nasal puffs every $4 \mathrm{~h}$ \\
\hline Vasopressin & IV infusion at a dose of $0.5-2.0 \mathrm{U} / \mathrm{h}$ \\
\hline
\end{tabular}

\section{Table 9: Common medicines causing liver- and} kidney-related adverse events

\begin{tabular}{|c|c|}
\hline Hepatotoxic medicines[43] & Nephrotoxic drugs ${ }^{[44]}$ \\
\hline Rifampicin & NSAIDs \\
\hline Isoniazid & Diuretics \\
\hline Pyrazinamide & ACE inhibitors \\
\hline NSAIDs & Aminoglycosides \\
\hline Full-dose ritonavir & Radiocontrast media \\
\hline Indinavir & Cisplatin \\
\hline Saquinavir & Quinine \\
\hline Zidovudine & Sulfonamides \\
\hline Didanosine & Hydralazine \\
\hline Stavudine & Lovastatin \\
\hline Nevirapine & Ethanol \\
\hline Sustained release niacin & Barbiturate \\
\hline Halothane & Penicillin \\
\hline Chloroform & Rifampicin \\
\hline Isoflurane, enflurane, desflurane & Cyclosporine \\
\hline Nitrous oxide & Tacrolimus \\
\hline Sulfasalazine & Acyclovir \\
\hline Gold salts & Methotrexate \\
\hline Azathioprine & Methysergide \\
\hline Methotrexate & Methyldopa \\
\hline Carbamazepine & Gold salts \\
\hline Valproic acid & Penicillamine \\
\hline Felbamate & Captopril \\
\hline Phenytoin & Mercury \\
\hline Chlorpromazine & Acetaminophen \\
\hline Haloperidol & Indinavir \\
\hline Risperidone & Lithium \\
\hline \multicolumn{2}{|l|}{ Quetiapine } \\
\hline \multicolumn{2}{|l|}{ Olanzapine } \\
\hline \multicolumn{2}{|l|}{ Clozapine } \\
\hline \multicolumn{2}{|l|}{ MAO inhibitors } \\
\hline \multicolumn{2}{|l|}{ Tacrine } \\
\hline Methyldopa & \\
\hline
\end{tabular}

NSAIDs: Nonsteroidal anti-inflammatory drugs; MAO: Monoamine oxidase; ACE: Angiotensin-converting enzyme

\subsubsection{Diabetes insipidus}

Desmopressin or vasopressin should be used early in the management of DI. The dose of desmopressin and vasopressin is given along with acceptable urine output as shown in Table 8.

Early use of antidiuretic agents in suspected DI may prevent physiological instability due to hypovolemia and hypothermia. 
Large amount of fluid loss in the urine should be replaced by intravenous fluids using balanced salt solution or fluids with low-sodium content ( $5 \%$ dextrose or $0.45 \%$ saline) to maintain sodium level between 135 and $145 \mathrm{mEq} / 1$ (Grade 1A).

\subsection{Metabolic derangement}

Intravenous fluids are also required to maintain normal fluid volume and electrolyte balance. Serum sodium and potassium should be monitored every 2-4 h (Grade 1B). Insulin infusion may be required for maintenance of normal blood glucose. Doses of insulin required for maintaining glucose control may be higher than normal. Blood sugars must be maintained in the range of $80-150 \mathrm{mg} / \mathrm{dl}$ (Grade 1A). ${ }^{[7]}$

\subsection{Temperature, respiration, and hematological management}

\subsubsection{Temperature}

Prevention of hypothermia is easier compared to its reversal. Active warming helps to prevent hypothermia. Efforts should be made to maintain temperature $>35^{\circ} \mathrm{C}$ (Grade 1A). ${ }^{[3]}$ Surface warming should be done in all patients with hypothermia. The patients with body temperature of $<34^{\circ} \mathrm{C}$ should be given core warming. In such cases, inhaled gases should be warmed and humidified using humidifier (Grade 2B). Intravenous fluid should also be warmed if large volumes are to be administered (Grade 2B).

\subsubsection{Respiration}

Respiratory passage should be clear without any obstruction. To achieve this, routine measures such as suctioning, positioning, and turning should be continued. A technique such as positive end-expiratory pressure helps to maintain oxygen delivery to the organs due to reduction in atelectasis. Interstitial fluid overload should be avoided. Oxygen saturations within normal limits and normocapnia should be maintained (Grade 1A).

\subsubsection{Hematological management}

In case of active bleeding, the cause of bleeding should be corrected at the earliest. ${ }^{[3]}$ Sometimes, transfusion of blood, coagulation factors, and platelets may be needed to correct severe anemia and/or coagulopathy (Grade 1B). In case of worsening coagulopathy, organ removal should be expedited. ${ }^{[34]}$ Transfusion of blood or blood products should be done only if necessary (Grade 2B).

\subsection{Infection management}

Donor should be infection free. Routine use of antibiotic prophylaxis is not warranted (Grade 2B). Antibiotic agents should be used on the basis of results of Gram's staining of aspirated secretion and positive cultures.

\subsection{Management of nutrition}

Nutrition should be continued as per standard ICU protocol (Grade 1B). Nutrition should be continued in patients awaiting consent for organ donation from the caregivers. Continuing enteral feeding in the potential donors may help in providing beneficial effects for organ functioning. ${ }^{[42,43]}$

\section{Medicines to be Avoided (Grade 1A)}

Drugs may cause adverse events related to different organs. Patient- and drug-related factors may be responsible for the toxic effects induced by medicines. ${ }^{[44]}$ Drug-related factors responsible for organ damage include drug's pharmacology, mechanism of action, dose, frequency of administration, duration, form of administration, and drug interaction potential. Medicines causing liver or kidney toxicity are listed in Table 9.

\section{Summary}

Brain stem death is usually followed by an expected pattern of complex multiple organ failure, hence an appropriate support to

Table 10: Checklist for the management of potential organ donors

\begin{tabular}{|c|c|c|c|c|c|}
\hline \multicolumn{2}{|c|}{ Basic monitoring } & \multicolumn{2}{|c|}{ Routine investigations } & \multicolumn{2}{|c|}{ Special management } \\
\hline Monitoring & Goal & Investigation & Goal & Management & Goal \\
\hline $\begin{array}{l}\text { Continuous monitoring } \\
\text { of core temperature }\end{array}$ & Body temperature $>35^{\circ} \mathrm{C}$ & Serum sodium & $135-145 \mathrm{mEq} / \mathrm{L}$ & $\begin{array}{l}\text { Peripheral warming } \\
\text { (and core warming, if } \\
\text { required) }\end{array}$ & Body temperature $>35^{\circ} \mathrm{C}$ \\
\hline Urine output & Urinary output, $\geq 1.0 \mathrm{ml} / \mathrm{kg} / \mathrm{h}$ & $\begin{array}{l}\text { Left ventricular } \\
\text { ejection fraction }\end{array}$ & $\geq 45 \%$ & $\begin{array}{l}\text { Electrolytes and IV } \\
\text { fluids }\end{array}$ & $\begin{array}{l}\text { Appropriate IV fluid choice } \\
\text { (preferably crystalloid, } \\
\text { balance salt fluid) }\end{array}$ \\
\hline \multirow[t]{5}{*}{ Oxygen saturation } & $>95 \%$ & & & $\begin{array}{l}\text { Mean arterial } \\
\text { pressure }\end{array}$ & $>60 \mathrm{mmHg}$ \\
\hline & & & & $\begin{array}{l}\text { Central venous } \\
\text { pressure }\end{array}$ & 6-8 $\mathrm{mmHg}$ \\
\hline & & & & Arterial $\mathrm{pH}$ & $7.35-7.45$ \\
\hline & & & & Nutritional support & As per ICU protocol \\
\hline & & & & Antibiotics & $\begin{array}{l}\text { Not required routinely; } \\
\text { should be given based on } \\
\text { culture, Gram staining } \\
\text { results }\end{array}$ \\
\hline
\end{tabular}


the donor before and after brain death can increase the number and quality of donor organs. The medical management of organ donor can be broadly divided into cardiovascular management, hormonal or management of metabolic derangement, management of temperature, respiration, hematological parameter, and nutritional support. Early identification of organs for donation helps to optimize the medical strategies. The guidance provided in this statement does not substitute proper clinical decision-making in particular case, but will help intensivists for the management of brain death for organ and tissue donation. Table 10 shows the checklist for the management of potential organ donors.

\section{Financial support and sponsorship}

Nil.

\section{Conflicts of interest}

There are no conflicts of interest.

\section{References}

1. Kumar L. Brain death and care of the organ donor. J Anaesthesiol Clin Pharmacol 2016;32:146-52.

2. Kutsogiannis DJ, Pagliarello G, Doig C, Ross H, Shemie SD. Medical management to optimize donor organ potential: Review of the literature. Can J Anaesth 2006;53:820-30.

3. McKeown DW, Bonser RS, Kellum JA. Management of the heartbeating brain-dead organ donor. Br J Anaesth 2012;108 Suppl 1:i96-107.

4. Bos EM, Leuvenink HG, van Goor H, Ploeg RJ. Kidney grafts from brain dead donors: Inferior quality or opportunity for improvement? Kidney Int 2007;72:797-805.

5. Rodrigues Sde L, Ferraz Neto JB, Sardinha LA, Araujo S, Zambelli HJ, Boin Ide $\mathrm{F}$, et al. Profile of effective donors from organ and tissue procurement services. Rev Bras Ter Intensiva 2014;26:21-7.

6. Mani RK, Amin P, Chawla R, Divatia JV, Kapadia F, Khilnani P, et al. Guidelines for end-of-life and palliative care in Indian Intensive Care Units' ISCCM consensus Ethical Position Statement. Indian J Crit Care Med 2012;16:166-81.

7. Wood KE, Becker BN, McCartney JG, D'Alessandro AM, Coursin DB. Care of the potential organ donor. N Engl J Med 2004;351:2730-9.

8. de Groot YJ, Jansen NE, Bakker J, Kuiper MA, Aerdts S, Maas AI, et al. Imminent brain death: Point of departure for potential heart-beating organ donor recognition. Intensive Care Med 2010;36:1488-94.

9. Dhanwate AD. Brainstem death: A comprehensive review in Indian perspective. Indian J Crit Care Med 2014;18:596-605.

10. National Guidelines for Organ and Tissue Donation Australasian Transplant Coordinators Association Incorporated $4^{\text {th }}$ Edition; 2008. Available from: http://www.atca.org.au/files/F.pdf. [Last accessed on 201410 Dec].

11. Government of India. Transplantation of Human Organs Act, 1994, Central Act 42; 1994. Available from: http://www.medindianet/tho/ thobill1 asp. [Last cited on 2007 Mar 09].

12. Shroff S. Legal and ethical aspects of organ donation and transplantation. Indian J Urol 2009;25:348-55.

13. Wijdicks EF. The diagnosis of brain death. $N$ Engl $J$ Med 2001;344:1215-21.

14. Goila AK, Pawar M. The diagnosis of brain death. Indian J Crit Care Med 2009;13:7-11.

15. van der Jagt M, Lin MS, Briegel J. Optimizing apnea testing to determine brain death. Intensive Care Med 2016;42:117-8.

16. Westphal GA, Garcia VD, Souza RL, Franke CA, Vieira KD, Birckholz VR, et al. Guidelines for the assessment and acceptance of potential brain-dead organ donors. Rev Bras Ter Intensiva 2016;28:220-55.
17. Pallis C. ABC of brain stem death. From brain death to brain stem death. Br Med J (Clin Res Ed) 1982;285:1487-90.

18. Sethi NK, Sethi PK. Brainstem death: Implications in India. J Assoc Physicians India 2003;51:910-1.

19. Weymann A, Schmack B, Szabo G. Pathophysiological consequences of brain death. Appl Cardiopulm Pathophysiol 2011;15:184-90.

20. Szabó G. Physiologic changes after brain death. J Heart Lung Transplant 2004;23 9 Suppl: S223-6.

21. Dujardin KS, McCully RB, Wijdicks EF, Tazelaar HD, Seward JB, McGregor CG, et al. Myocardial dysfunction associated with brain death: Clinical, echocardiographic, and pathologic features. J Heart Lung Transplant 2001;20:350-7.

22. Novitzky D, Wicomb WN, Cooper DK, Rose AG, Reichart B. Prevention of myocardial injury during brain death by total cardiac sympathectomy in the Chacma baboon. Ann Thorac Surg 1986;41:520-4.

23. Lemke DM. Sympathetic storming after severe traumatic brain injury. Crit Care Nurse 2007;27:30-7.

24. Totsuka E, Dodson F, Urakami A, Moras N, Ishii T, Lee MC, et al. Influence of high donor serum sodium levels on early postoperative graft function in human liver transplantation: Effect of correction of donor hypernatremia. Liver Transpl Surg 1999;5:421-8.

25. Finfer S, Bohn D, Colpitts D, Cox P, Fleming F, Barker G. Intensive care management of paediatric organ donors and its effect on post-transplant organ function. Intensive Care Med 1996;22:1424-32.

26. Goarin JP, Cohen S, Riou B, Jacquens Y, Guesde R, Le Bret F, et al. The effects of triiodothyronine on hemodynamic status and cardiac function in potential heart donors. Anesth Analg 1996;83:41-7.

27. Novitzky D, Cooper DK, Reichart B. Hemodynamic and metabolic responses to hormonal therapy in brain-dead potential organ donors. Transplantation 1987;43:852-4.

28. Phongsamran PV. Critical care pharmacy in donor management. Prog Transplant 2004;14:105-11.

29. Amado JA, López-Espadas F, Vázquez-Barquero A, Salas E, Riancho JA, López-Cordovilla JJ, et al. Blood levels of cytokines in brain-dead patients: Relationship with circulating hormones and acute-phase reactants. Metabolism 1995;44:812-6.

30. Shah V, Bhosale G. Organ donor problems and their management. Indian J Crit Care Med 2006;10:29-34.

31. Reilly PM, Morgan L, Grossman MD, Shapiro MB, Anderson HL, Hawtorne RV, et al. Lung procurement from solid organ donors: Role of fluid resuscitation in procurement failures. Chest 1996;110:222S.

32. The ANZICS Statement on Death and Organ Donation. $4^{\text {th }}$ ed.; 2013. Available from: http://www.anzics.com.au/Downloads/ANZICS $\% 20$ Statement $\% 20$ on $\% 20 \% 20$ Death $\% 20$ and $\% 20$ Organ $\% 20$ Donation $\% 20$ Edition\%203.2.pdf. [Last accessed on 2014 Dec 10].

33. O'Malley CM, Frumento RJ, Hardy MA, Benvenisty AI, Brentjens TE, Mercer JS, et al. A randomized, double-blind comparison of lactated Ringer's solution and $0.9 \% \mathrm{NaCl}$ during renal transplantation. Anesth Analg 2005;100:1518-24.

34. Powner DJ, Darby JM, Kellum JA. Proposed treatment guidelines for donor care. Prog Transplant 2004;14:16-26.

35. Cittanova ML, Leblanc I, Legendre C, Mouquet C, Riou B, Coriat P. Effect of hydroxyethyl starch in brain-dead kidney donors on renal function in kidney-transplant recipients. Lancet 1996;348:1620-2.

36. IwaiA, Sakano T, Uenishi M, Sugimoto H, Yoshioka T, Sugimoto T. Effects of vasopressin and catecholamines on the maintenance of circulatory stability in brain-dead patients. Transplantation 1989;48:613-7.

37. Shemie SD, Ross H, Pagliarello J, Baker AJ, Greig PD, Brand T, et al. Organ donor management in Canada: Recommendations of the forum on medical management to optimize donor organ potential. CMAJ 2006; 174:S13-32.

38. Vaghadia H. Atropine resistance in brain-dead organ donors Anesthesiology 1986;65:711-2.

39. Zaroff JG, Rosengard BR, Armstrong WF, Babcock WD, D'Alessandro A, Dec GW, et al. Consensus conference report: Maximizing use of organs recovered from the cadaver donor: Cardiac recommendations, March 28-29, 2001, Crystal City, VA. Circulation 2002;106:836-41. 
40. Randell TT, Höckerstedt KA. Triiodothyronine treatment in brain-dead multiorgan donors - A controlled study. Transplantation 1992;54:736-8.

41. Follette DM, Rudich SM, Babcock WD. Improved oxygenation and increased lung donor recovery with high-dose steroid administration after brain death. J Heart Lung Transplant 1998;17:423-9.
42. Singer P, Cohen J, Cynober L. Effect of nutritional state of brain-dead organ donor on transplantation. Nutrition 2001;17:948-52.

43. Singer P, Shapiro H, Cohen J. Brain death and organ damage: The modulating effects of nutrition. Transplantation 2005;80:1363-8.

44. Pandit A, Sachdeva T, Bafna P. Drug-induced hepatotoxicity: A review. J Appl Pharm Sci 2012;2:233-43. 